\title{
The Uronarti Regional Archaeological Project: Second Cataract fortresses and the Western Desert of Sudan
}

\author{
Evan I. Levine ${ }^{1, *}$, Miriam A.W. Rothenberg ${ }^{1}$, Oren Siegel ${ }^{2}$, \\ Christian Knoblauch ${ }^{3}$, Laurel Bestock ${ }^{1} \&$ Lutz Klein $^{1}$
}

The Batn el-Hagar in Sudan has traditionally been characterised as sparsely occupied during the Middle Kingdom Period, with most activity limited to the Egyptian fortresses along the Second Cataract. A new survey programme undertaken by the Uronarti Regional Archaeological Project offers evidence for a more richly occupied landscape.

Keywords: Sudan, Nile Cataract, Middle Kingdom, survey, satellite imagery

\section{Introduction}

The Batn el-Hagar (Belly of Stone) is a 160km-long stretch of the Nile Valley in Sudan above the Second Nile Cataract where the river passes over a shallow bed in the exposed granite basal complex. Characterised by hyperaridity, a dearth of arable land and a very low carrying capacity, this region appears to have always been a challenging environment, especially since the introduction of agricultural subsistence strategies (Hewes 1966: 42-43). In the area of the Semna Cataract, where our work is focused, larger populations are limited to the Nubian Christian period (AD 641-1400), when new irrigation technology and cultural factors favoured settlement; and the Egyptian Middle Kingdom (2010-1685 BC), when the cataract became Egypt's southern border with the state of Kush (Kerma).

Since 2012, the Uronarti Regional Archaeological Project (URAP) has been excavating the Middle Kingdom fortress of Uronarti, just south of the Second Cataract (Knoblauch et al. 2013; Bestock 2017). The fortress is one of five built by Senwosret III to consolidate economic and military control of the new border zone (Knoblauch 2019) between Egypt and Nubia. Based on earlier survey fieldwork by Mills (1965, 1973; Edwards \& Mills 2013), this zone was previously believed to be sparsely populated, with Egyptian activity restricted to the formal fortress structures and their immediate environs. The URAP implemented a programme of systematic extensive survey of the Western Desert near Uronarti to test this 'minimalist model' of Egyptian occupation, documenting over 100 distinct archaeological features, including several sites of Middle Kingdom occupation (Figure 1).

1 Joukowsky Institute for Archaeology and the Ancient World, Brown University, 60 George Street, Providence RI 02912, USA

2 Department of Near Eastern Languages and Civilizations, University of Chicago, 5828 South University Avenue, Chicago IL 60637, USA

3 Department of Classics, Ancient History and Egyptology, Swansea University, Sketty, Swansea SA2 8PZ, UK

* Author for correspondence (Email: evan_levine@brown.edu) 


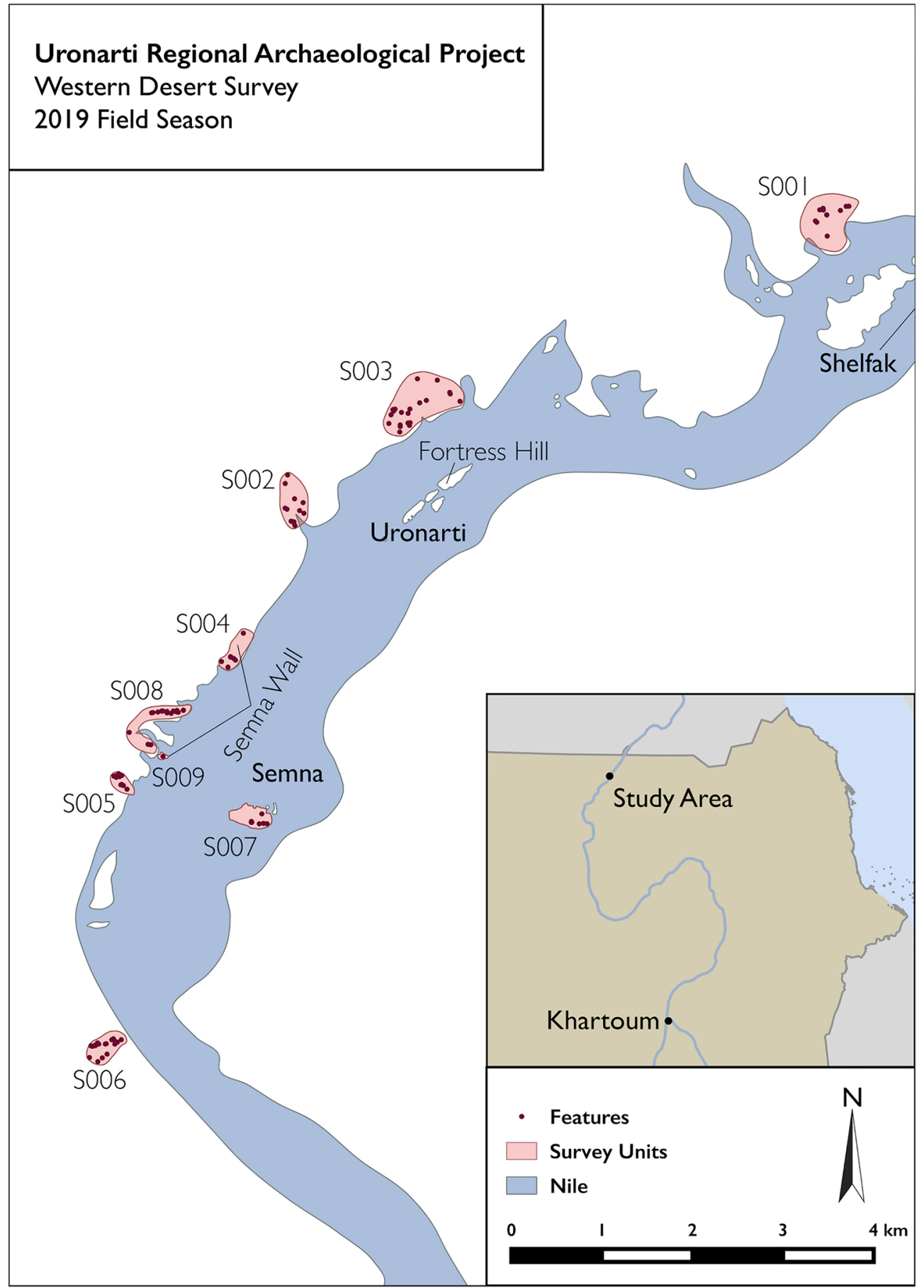

Figure 1. Survey area with sites of interest located.

(C) Antiquity Publications Ltd, 2019 


\section{Methodology}

The survey team employed satellite remote-sensing analysis, systematic extensive pedestrian survey, artefact analysis, photogrammetric modelling and architectural recording to locate and document a wide range of archaeological features and artefacts. Data were collected with a bespoke paperless recording system, developed on-site and continually modified throughout the season in response to user feedback (Figure 2).

Areas of potential interest were located through visual analysis of pansharpened, high resolution $(0.46 \mathrm{~m})$ WorldView 2 satellite imagery provided by the Digital Globe Foundation. The images also provided recent data on Nile water levels and landscape change over the past year. The results of this analysis were compared with longer-term data from Google Earth and published data from previous surveys of the area by Steindorff (Felber et al. 2000), Vercoutter (1957) and Mills (1965, 1973; Edwards \& Mills 2013). While previous surveys were primarily concerned with low-elevation features close to the pre-dammed route of the Nile, the URAP's investigations focused on features over $180 \mathrm{~m}$ asl.

Survey data were collected using a structured query language (SQL)-based paperless recording system, accessed through a FileMaker Go user interface and facilitating multimedia data collection and evaluation. This interface was constructed within the framework of the broader URAP recording system (Brown University n.d.), streamlining artefact registration

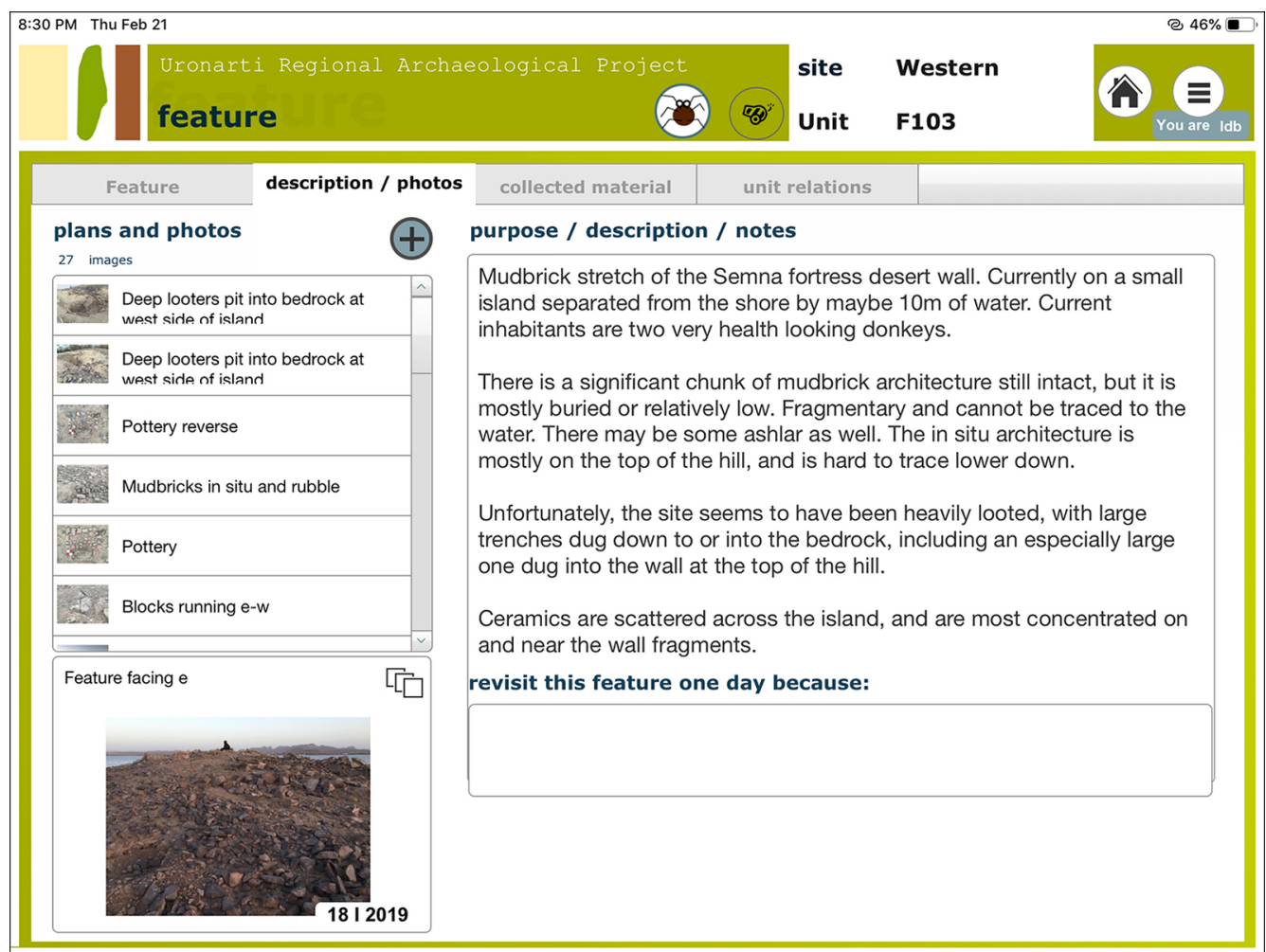

Figure 2. Screenshot of the paperless recording system. 
and analysis, and facilitating comparison with excavated material culture and architectural features. Once sites were identified, features were recorded and surface ceramics, lithics and other cultural materials were collected, quantified and documented. This information was entered into the paperless database in real time; ceramics were photographed, and diagnostic sherds collected for analysis.

Select features were recorded in more detail using a combination of photogrammetry and topographic survey; aerial photographs were taken by a kite-mounted Olympus TG-4 camera alongside manual photography using the same camera. These 16-megapixel photographs were processed into three-dimensional models, digital elevation models and orthophotographic meshes with high metric accuracy (Sapirstein \& Murray 2017). Spatial referencing was provided by ground control points recorded using Emlid Reach RS+ Real-Time-Kinematic Differential GPS units with a fixed base located at the URAP campsite and a rover collecting corrected data with sub-centimetre accuracy from a distance of up to $6 \mathrm{~km}$.

\section{Results}

In total, 115 features were documented, in nine survey units. The majority of archaeological features were either small dry-stone constructions (huts), often circular or semi-circular $(\mathrm{n}=95)$, or monumental walls probably associated with the Middle Kingdom fortifications $(n=3)$. These features were not discrete, however, often being in close proximity to one another. Other documented features included graves, cleared areas, a mortared stone building of uncertain date, modern ephemeral reed-and-wood huts used by local fishermen and at least one area that had been heavily modified by manual surface mining for gold. The water level of Lake Nubia was exceptionally high during the survey, which was undertaken in January 2019, and many features that had been identified previously by the URAP (Knoblauch et al. 2013) were inundated, along with areas normally under intensive cultivation and pasture.

Of note is the rediscovery and documentation of two sections of a monumental defensive wall that ran for $5 \mathrm{~km}$ along the west bank between the now-submerged fortress of Semna and Uronarti (Edwards \& Mills 2013). As with a comparable Middle Kingdom wall at the First Cataract, documented between Elephantine and Shellal (von Pilgrim et al. 2011: 135-37), the Semna-Uronarti wall was probably intended to protect a heavily utilised land route that bypassed a poorly navigable stretch of the river. Mills (1973: 206, pl. 2) cleaned and documented a section of the Semna-Uronarti wall during his fieldwork, and Knoblauch et al. (2013: 138) recorded a segment that consisted of mud-bricks built directly onto the bedrock. At the two sections of wall currently above water, the URAP noted construction in both mudbrick and stone; the stonework included dry fieldstones, in the higher courses, and cut foundation blocks. The northern section of the wall (F050), stretching some $303 \mathrm{~m}$ along a ridge, is primarily preserved as a series of parallel dry-stone linear features with occasional exposed mud-brick (Figure 3). The southern section of the wall (F103), extending 106m, consists of a mud-brick superstructure atop regularised and well-built stone foundations (Figure 4). The heterogeneity of construction techniques presumably reflects adaptations by the Egyptian architects to local topography and other variables; for example, the nature of the subsurface and the distance to locally available resources.

(C) Antiquity Publications Ltd, 2019 


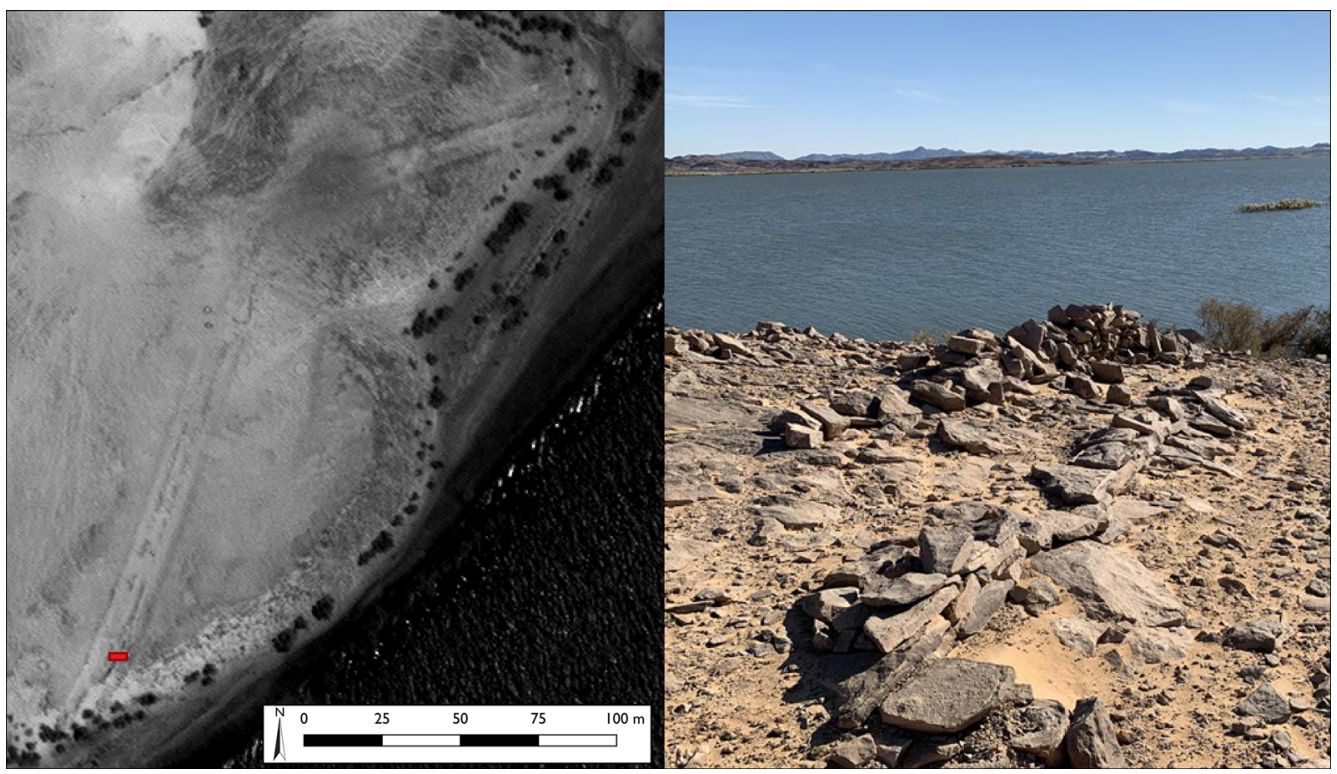

Figure 3. F050, Semna Wall north.

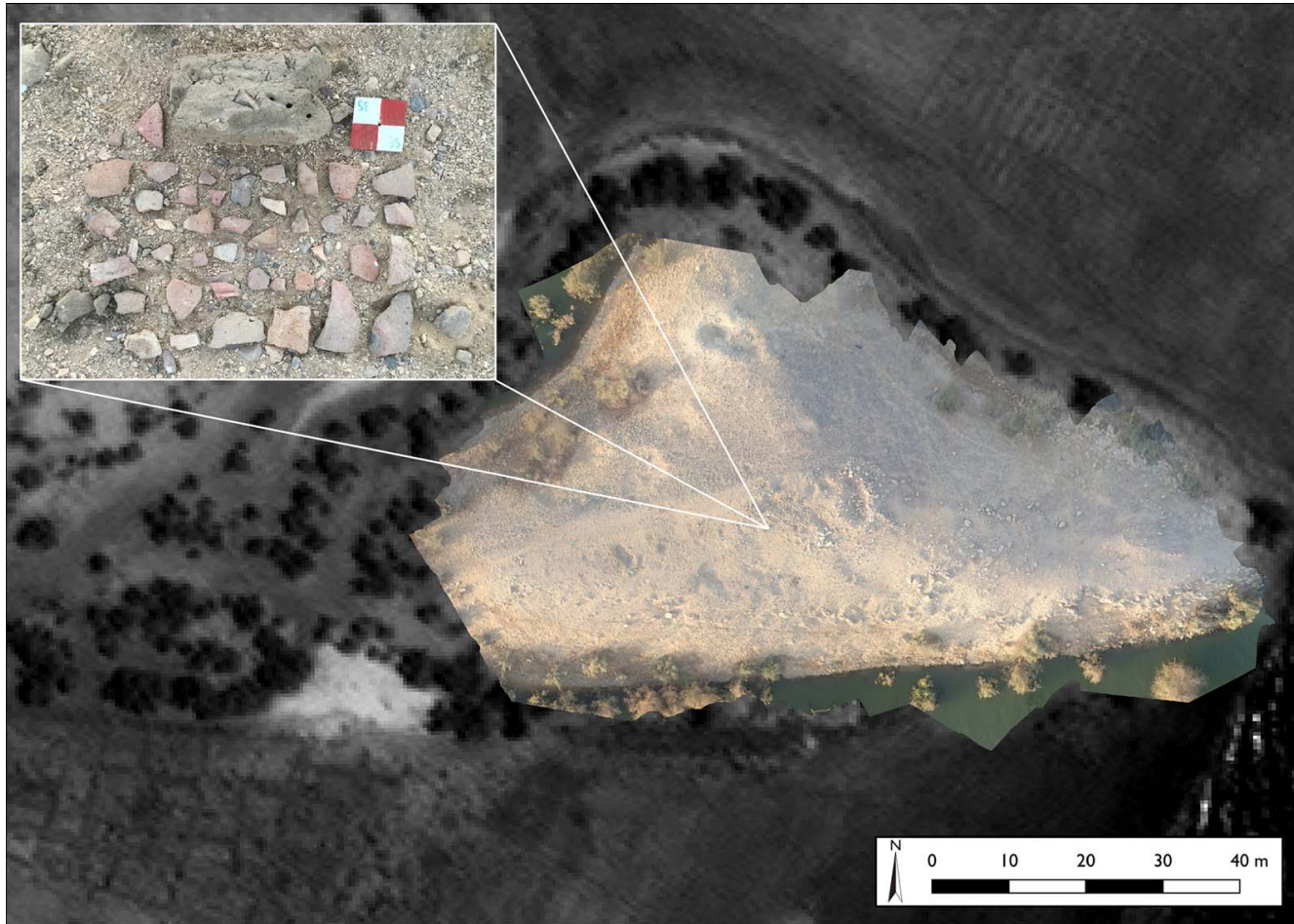

Figure 4. F103, Semna Wall south.

(C) Antiquity Publications Ltd, 2019 
Other stretches of dry-stone walling were also noted, often formed by piled stones stretching along ridgelines and saddles (Figure 5). Surface pottery was found at each of these wall features. Interestingly, the dateable surface ceramic assemblage was entirely of Egyptian Middle Kingdom date, and circular dry-stone constructions (huts) were often located in the immediate vicinity (Figure 6). Earlier surveys (Borchardt 1923: 24; Edwards \& Mills 2013: 10) found a much longer $(3 \mathrm{~km})$ wall of the same type on the eastern bank near Kumma. Whether such walls were simply a means of regularising or augmenting the topography during the Middle Kingdom, or were related to hunting activities, as in Middle Nubia where such walls are common (Edwards \& Mills 2013: 10), is difficult to determine on current evidence.

The URAP also recorded several ridgetop clusters of dry-stone features, along with numerous other constructions across the landscape built from local bedrock. Small assemblages of surface artefacts were occasionally recorded in association with these features, and all diagnostic ceramic sherds were exclusively of Middle Kingdom date. Infrequent chipped- and ground-stone tools were also recorded, most probably alluding to on-site food preparation (hunting or grain processing) during this same period. Artefacts firmly dating to other periods were notably absent, other than traces of modern local lifeways (clothing, medicine, butchered animals, fishing nets and the like).

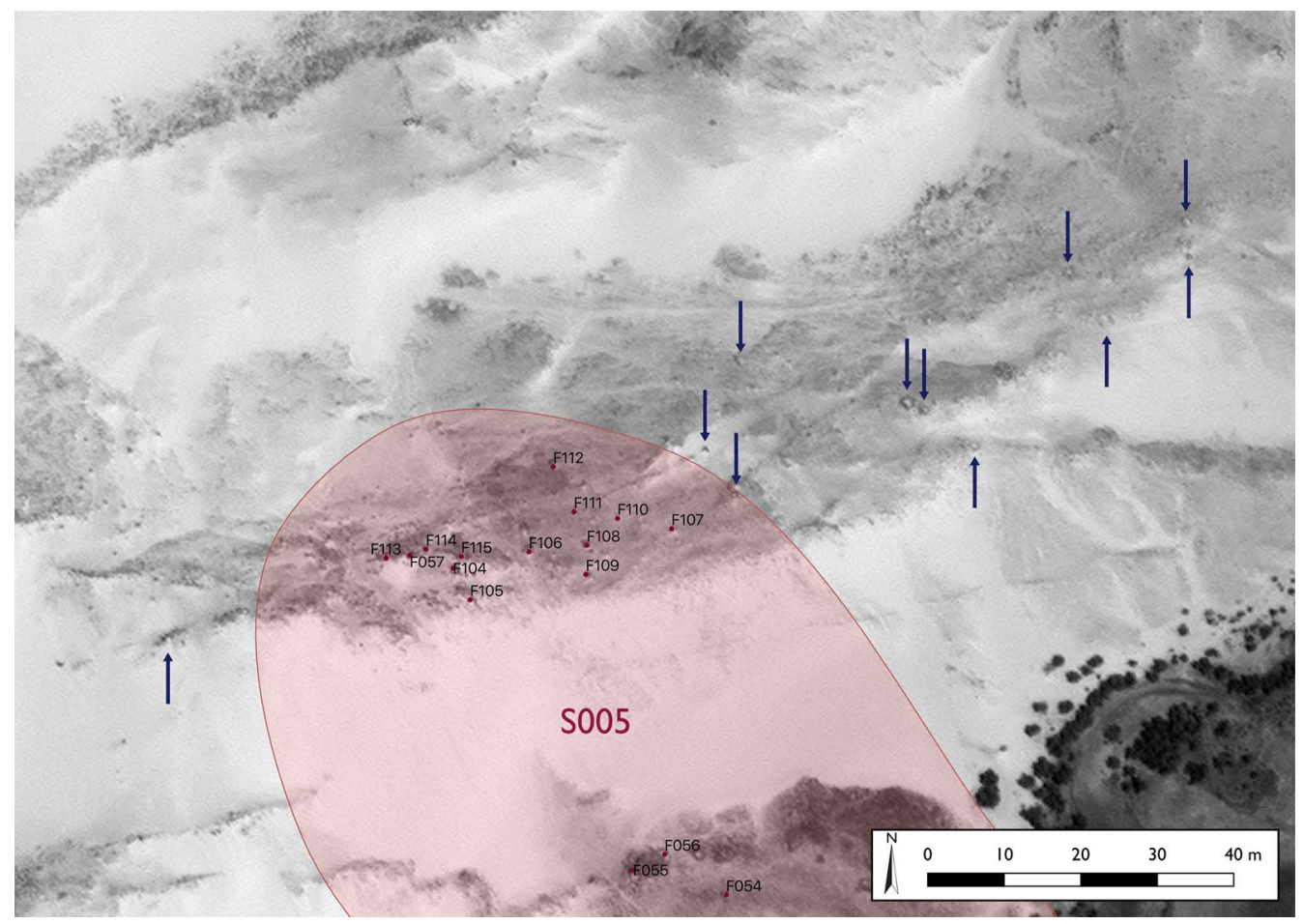

Figure 5. S005 and other features detected with WV2 imagery.

(C) Antiquity Publications Ltd, 2019 


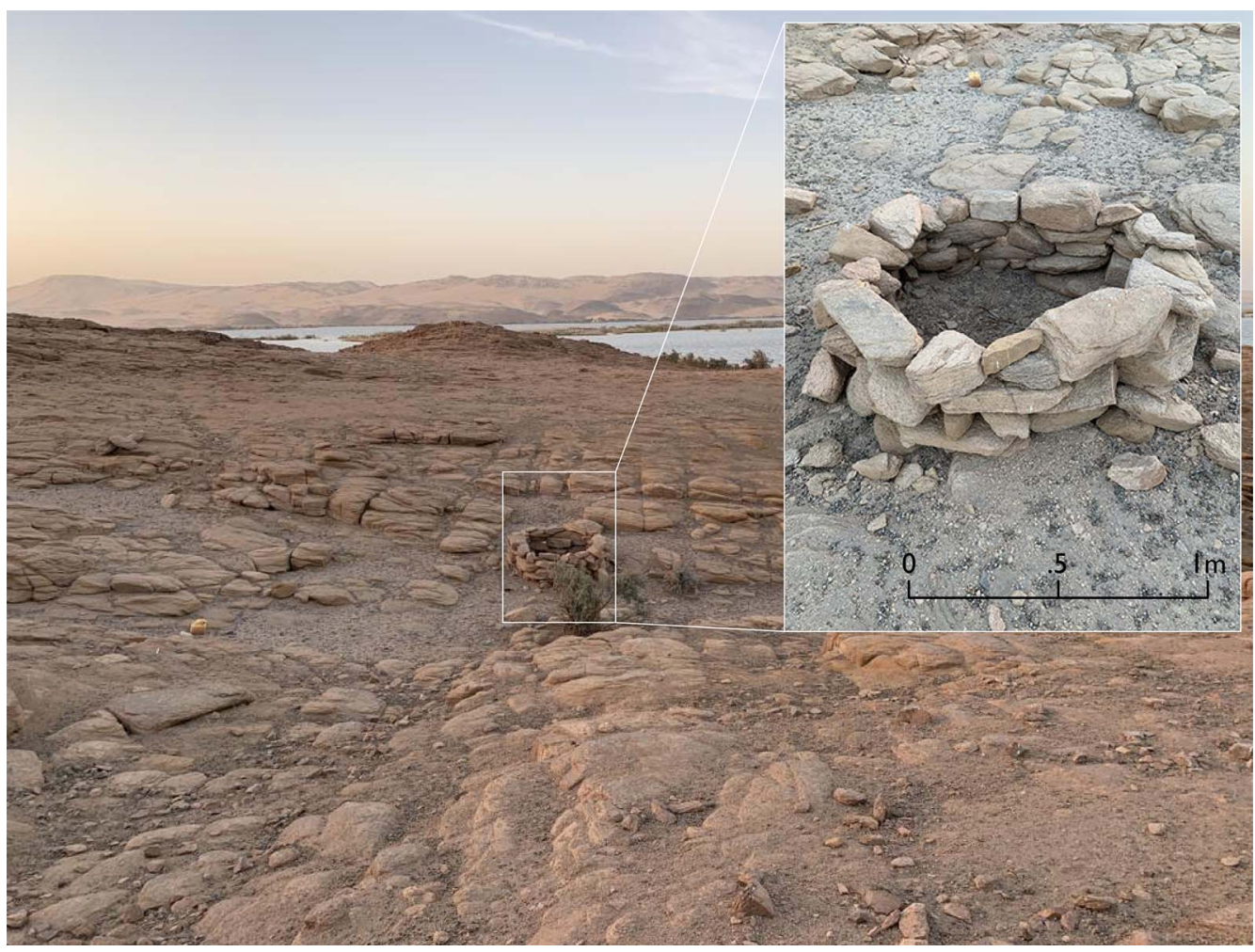

Figure 6. F082, a 'typical' circular dry-stone structure.

\section{Implications}

Perhaps the most important trend in our survey results is the proliferation of Egyptian pottery beyond the immediate environs of the Uronarti fortress, associated with dry-stone architecture at elevations far removed from the ancient course of the Nile. Combined with the extra-mural stone settlement that the URAP documented on Uronarti Island (Bestock \& Knoblauch 2015), these finds suggest that the Egyptian presence in this inhospitable border region was diverse, and certainly not confined to the formal fortress structures as hitherto believed. Determining discrete functions for these sites is difficult without excavation, and more systematic survey is required to highlight settlement patterns on a diachronic scale. Future field seasons will extend this survey in both the Eastern and Western Deserts. Excavation of select dry-stone structures recorded in 2019 will also be incorporated in order to understand the function of these features and their direct relationship with material culture emanating from nearby fortresses.

\section{Acknowledgements}

The authors would like to thank the Sudan National Corporation of Antiquities and Museums-in particular Elnzeer Tirab—and the members of our survey team: Abigail Stoner, Allison McCoskey, Anna Soifer and Lyndelle Webster. Many thanks to the DigitalGlobe Foundation for providing satellite imagery. Finally, we thank the many local fishermen and shepherds who kindly facilitated our research and provided welcome hospitality in the Western Desert.

(C) Antiquity Publications Ltd, 2019 


\section{References}

Bestock, L. 2017. Forgotten fortress: returning to Uronarti. Near Eastern Archaeology 80: 154-65. http://doi.org/10.5615/neareastarch.80.3.0154

Bestock, L. \& C. Knoblauch. 2015. Living beyond the walls: new evidence for Egyptian colonialism at Uronarti, Nubia. Antiquity Project Gallery 89(344). Available at: https://antiquity.ac.uk/projgall/bestock344 (accessed 15 October 2019).

Borchardt, L. 1923. Altägyptische Festungen an der zweiten Nilschnelle. Leipzig: Otto Harrassowitz.

Brown University. n.d. Technology. Available at: http://blogs.brown.edu/archaeology/fieldwork/ uronarti/technology/ (accessed 15 October 2019).

Edwards, D.N. \& A.J. Mills. 2013. 'Pharaonic' sites in the Batn el-Hajar-the 'archaeological survey of Sudanese Nubia' revisited. Sudan \& Nubia 17: 8-17.

Felber, H., F. Kampp-Seyfried, A. Spiekermann \& F. Steinmann. 2000. Karawane: zum Orakel des Amun. Steindorffs expedition nach Amarna, Siwa und Nubien 1899/1900. Leipzig: Kleine Schriften des Ägyptischen Museums der Universität Leipzig.

Hewes, G. 1966. Prehistoric investigations on the West Bank in the Batn el-Hagar by the University of Colorado Nubian Expedition. Kush 14: 25-43.
Knoblauch, C. 2019. Middle Kingdom fortresses, in D. Raue (ed.) Handbook of Nubia: 367-91. Boston (MA) \& Berlin: De Gruyters. https://doi.org/10.1515/9783110420388-016

Knoblauch, C., L. Bestock \& A. Makovics. 2013. The Uronarti Regional Archaeological Project: final report of the 2012 survey. Mitteilungen des Deutschen Archäologischen Instituts Abteilung Kairo 69: 103-42.

Mills, A.J. 1965. The reconnaissance from Gemai to Dal: a preliminary report. Kush 13: 1-12.

- 1973. The archaeological survey from Gemai to Dal: report on the 1965-66 season. Kush 15: 200-10.

von Pilgrim, C., W. Müller \& L. Werlen. 2011. The town of Syene. Report on the $8^{\text {th }}$ season in Aswan. Mitteilungen des Deutschen Archäologischen Instituts Abteilung Kairo 67: 125-61.

Sapirstein, P. \& S. Murray. 2017. Establishing best practices for photogrammetric recording during archaeological fieldwork. Journal of Field Archaeology 42: 337-50. http://doi.org/10.1080/00934690.2017. 1338513

Vercoutter, J. 1957. Archaeological survey in the Sudan, 1955-57. Sudan Notes and Records 38: $111-17$.

Received: 2 March 2019; Revised: 22 June 2019; Accepted: 26 June 2019

(C) Antiquity Publications Ltd, 2019 